\title{
26 Research Square \\ Investigating the role of gut bacterial ClpB-like gene function in obesity
}

\author{
María Arnoriaga-Rodríguez \\ Jordi Mayneris-Perxachs \\ Aurelijus Burokas \\ Vicente Pérez-Brocal \\ Andrés Moya \\ Manuel Portero-Otin \\ Wifredo Ricart \\ Rafael Maldonado \\ José Manuel Fernández Real
}

\section{Video Byte}

Keywords: microbiome, bacterial gene function, body weight regulation, obesity, ClpB, chaperone, bacteria, gut, microbiota, fecal transplantation, metabolomics, Microbiome

Posted Date: October 28th, 2020

DOI: https://doi.org/10.21203/rs.3.rs-99189/v1

License: (9) (1) This work is licensed under a Creative Commons Attribution 4.0 International License. Read Full License 


\section{Abstract}

Obesity is rapidly becoming a critical health concern globally. Growing evidence connects the microbiotagut-brain axis to the pathophysiology of obesity. Gut bacteria can produce proteins that influence our hormonal and metabolic pathways, regulating satiety and hunger hormones. One such protein is $\mathrm{ClpB}$, a chaperone protein expressed by E. coli. ClpB mimics the body's hormones -- promoting satiety and regulating energy, blood pressure, and growth. A recent study examined the association between gut bacterial ClpB-like gene function and obesity. Using DNA sequencing and metabolomics, the researchers examined gut bacteria from people with or without obesity. They found that the bacterial species associated with more ClpB-like gene function were reduced in subjects with obesity and important bacterial characteristics, such as high ClpB expression and a negative association with obesity, could be transferred to mice through fecal transplantation. While more experimental and long-term studies are needed, the results suggest that bacterial ClpB expression could lead to increased satiety and decreased fat mass in the long term, providing important insight to combat obesity. 